\title{
PERFORMANCE OF WIRELESS MEASUREMENT SYSTEM FOR SOIL PROPERTIES MONITORING
}

\author{
TSVETELINA GEORGIEVA ${ }^{1 *}$, NADEZHDA PASKOVA ${ }^{1}$, \\ GERGANA KUNCHEVA ${ }^{1}$, PLAMEN DASKALOV ${ }^{1}$ \\ ${ }^{1}$ University of Ruse “Angel Kanchev”, Studentska8, Ruse, 7000, Bulgaria
}

\begin{abstract}
A developed wireless microprocessor system based on ATmega328P microcontroller and Arduino sensors for measurement of soil properties is described in the paper. The accuracy of the proposed system is analized during the measurement of basic soil parameters - electrical conductivity and acidity. The system has been experimentally tested with soil samples from eight soil types and soil solution. The results for the soil parameters obtained with the wireless measurement system are compared with a reference measuring instrument. The presented wireless system for soil parameters monitoring shows good measurement accuracy sufficient for engineering research.
\end{abstract}

Keywords: soil, microprocessor system, electro conductivity, acidity

\section{INTRODUCTION}

\subsection{Quality parameters of soil}

The soil is the surface layer of the Earth, with complex composition and structure. It has the unique fertility property. Soil fertility provides plants with all necessary elements (nutrients, water, air) for their development and productivity. The different regions of the Earth have different soil types with specific properties and parameters. They are determined by the climate, the material scale, the vegetation, the relief.

Soil properties are separated into three classes [1]:

- physical: bulk density, relative, porosity, water permeability.

- chemical: They are determined by the content of mineral substances, various organic substances and the acidalkaline reaction of the medium. Organic soil composition consists of undeveloped dead organic matter from plant debris and recently dead animal species, half-decomposed dead organic matter, decomposed dead organic matter, much of which is contained in organic humus.

- biological: properties of the soil are determined by the different organisms involved in the soil-forming process.

These properties are general indicators of soil quality. Soil quality indicators are very important for evaluation of soil status, for adequate solutions and applications of management practices and techniques, for collection of necessary information to determine the soil areas trends.

Soil types in Bulgaria are as follow [2]:

$>$ North part of Bulgaria:

- Black Sea - 20\% of the country's territory; thickest humus horizon up to $1.50 \mathrm{~m}$, grainy structure;

- Gray forest - $16 \%$ of the country's territory; distributed in hilly regions up to $800 \mathrm{~m}$; shallow humus horizon;

- Brown forest - thin humus horizon; spread from 800 to $1500 \mathrm{~m}$.

*Corresponding author, email: cgeorgieva@uni-ruse.bg

(C) 2018 Alma Mater Publishing House 
South part of Bulgaria:

- Cinnamon soils - $22 \%$ of the country's territory;

- Resins - All kinds of crops are grown;

- Brown forest - spread to $1500 \mathrm{~m}$;

- Mountain - meadows - accumulate a lot of water, nothing is grown on them;

- Rendzins (humus-carbonate) - the most barren soil, located around rocks, caves;

- Alluvial - meadow - very fertile soils.

Main quality indicators of soil are acidity, electrical conductivity and humidity. Soil moisture is the main indicator for estimating agricultural drought. Moisture content in soil can be expressed in terms of soil water content or water potential. The drier soil has greater water potential, and the water is more difficult to extract from the soil. On the other hand the excess moisture degrades the aeration of the soil, making it difficult to breathe the roots and the development of the soil microorganisms. The moisture content of the soil or the water content of the soil can be expressed as a percentage by weight (moisture in percentage of the weight of the absolutely dry soil) and is determined by the thermostatic weight method or by volume percent or parts $-\mathrm{cm}^{3}$ of water or soil. The water potential of the soil describes how well the soil holds the water. Soil pressure is another term used to describe the water potential of the soil.

Soil acidity and alkalinity are measured in units of $\mathrm{pH}$ [3]. The soil response is indicated by the $\mathrm{pH}$ index. This index is a number that reflects the concentration of hydrogen ions in the soil solution. Soil $\mathrm{pH}$ has an important role in the proper growth of crops and yields. The main reason this parameter is to be regulated is that it depends on the absorption of nutrients. The optimum $\mathrm{pH}$ is different for different crops. The numerical value of the $\mathrm{pH}$ is 7 when neutral. At a value greater than 7, the reaction is alkaline, and at a value below 7 the reaction is acidic. The influence of soil $\mathrm{pH}$ on crop farming is significant. The soil $\mathrm{pH}$ factor influences the many physical, chemical and biological responses necessary for the survival, growth and yield of agricultural crops. The absorption of nutrients is strongly influenced by $\mathrm{pH}$ and is probably the second most important reason for soil $\mathrm{pH}$ regulation. When calcium acidity increases, the calcium carbonates dissolve and the physical properties of the soil deteriorate. High acidity adversely affects plants, reduces productivity, and often leads to plant death. Soil response at different $\mathrm{pH}$ values is presented in Table 1.

Table.1. Soil response at different $\mathrm{pH}$ values.

\begin{tabular}{|l|c|c|}
\hline \multicolumn{1}{|c|}{ Soil reaction } & $\mathrm{pH}$ in KCI & $\mathrm{pH}$ in $\mathrm{H}_{2} \mathrm{O}$ \\
\hline Very strong acid & under 4.0 & Under 4.0 \\
\hline Highly acidic & $4.1-4.5$ & $4.1-5.0$ \\
\hline Moderately acidic & $4.6-5.0$ & $5.1-6.0$ \\
\hline Slightly acidic & $5.1-5.6$ & $6.1-6.5$ \\
\hline Neutral & $5.7-6.2$ & $6.6-7.0$ \\
\hline Slightly alkaline to alkaline & up 6.3 & $7.1-8.5$ \\
\hline Highly alkaline & & Up to 8.6 \\
\hline
\end{tabular}

Soil $\mathrm{pH}$ affects in many aspects of crop production. including nutrient digestibility. metal toxicity potential. efficacy and degradation of soil herbicides. and the fixing of the legume nitrogen. A soil $\mathrm{pH}\left(\mathrm{CaCl}_{2}\right)$ of 5.2 to 8.0 provides optimum conditions for most agricultural plants.

Soil electrical conductivity (EC) is a measurement that correlates with soil properties that affect crop productivity. soil texture. drainage conditions. organic matter level. salinity. and other characteristics. Soil conductivity is used to characterize various soil properties such as residual humidity. salinity. nutrient concentration. and others. Soil conductivity strongly correlates with particle size and soil structure. Salinity of the soil is extremely important during germination and germination. Electricity is a measure of salt content. Degree of soil salinity and impact on crops are presented in Table 2.

The electrical conductivity of a soil solution or extract shows the concentration of total soluble salts in the solution. thus reflecting the degree of salinity of the soil. The unit of measurement is milliseconds per centimeter $(\mathrm{mS} / \mathrm{cm})$. The electrical conductivity varies not only for the concentration of salts present in the solution but also for the chemical composition of the soil solution.

Table. 2. Degree of soil salinity and impact on crops. 


\begin{tabular}{|c|c|c|c|c|}
\hline $\begin{array}{c}\mathrm{EC} \\
(\mathrm{mS} / \mathrm{cm})\end{array}$ & $\begin{array}{l}\text { Degree of soil } \\
\text { salinity }\end{array}$ & $\begin{array}{l}\text { Degree of } \\
\text { impact on } \\
\text { growth }\end{array}$ & Plant growth & Tolerance of crops \\
\hline $0-2$ & Not salnity & Very low & Insignificantly & \\
\hline $2-4$ & Slightly salted & Low & Reduction in yields of susceptible crops & $\begin{array}{l}\text { Beans. peas. corn. } \\
\text { soy. sunflower }\end{array}$ \\
\hline $4-8$ & Average salted & Average & Reducing yields of many crops & $\begin{array}{l}\text { Oats. wheat. barley. } \\
\text { rice. alfalfa }\end{array}$ \\
\hline $8-16$ & Strongly salted & High & $\begin{array}{c}\text { Only some tolerant crops can yield } \\
\text { satisfactory yields }\end{array}$ & High grain grass \\
\hline$>16$ & $\begin{array}{l}\text { Very strongly } \\
\text { salted }\end{array}$ & Very high & $\begin{array}{l}\text { Only some tolerant forage grasses can } \\
\text { grow under these conditions }\end{array}$ & \\
\hline
\end{tabular}

\subsection{Measurement of main quality indicators of soil}

Methods for water content measurement in soil could be direct and indirect. Direct soil testing is based on measurements and calculations. and is performed in a laboratory using a precision instrument and a furnace. Indirectly. soil moisture is measured as a result of the dependence between soil moisture and its dielectric constant using capacitive sensors. Two types of sensors are discussed in [4] for measurement of electrical conductivity (EC). For the purpose of precise agriculture more appropriate is non-contact method for conductivity measurement. Usually for EC measurement of soil is used soil solution in a ratio of soil and distilled water in proportion 1:5.

Microprocessor system based on microprocessor is proposed in [5]. The system functionality allow to measurement different soil quality parameters with allowable accuracy but the application is limited to few parameters. NIR spectroscopy is used for soil classification and soil properties determination [6]. This method is too complicate and require a lot of equipment. software applications and has high price.

The aim of the paper is to present a performance of wireless microprocessor system based on ATmega328P microcontroller and Arduino sensors for measurement of soil properties and to assess the accuracy of the proposed system during the comparative measurement of basic soil parameters - electrical conductivity and acidity between the system and reference devices.

\section{EXPERIMENTAL SETUP}

\subsection{System overview}

The wireless systems for soil monitoring includes coordinator and sensor node. Block diagram of the proposed system is shown on Figure 1.

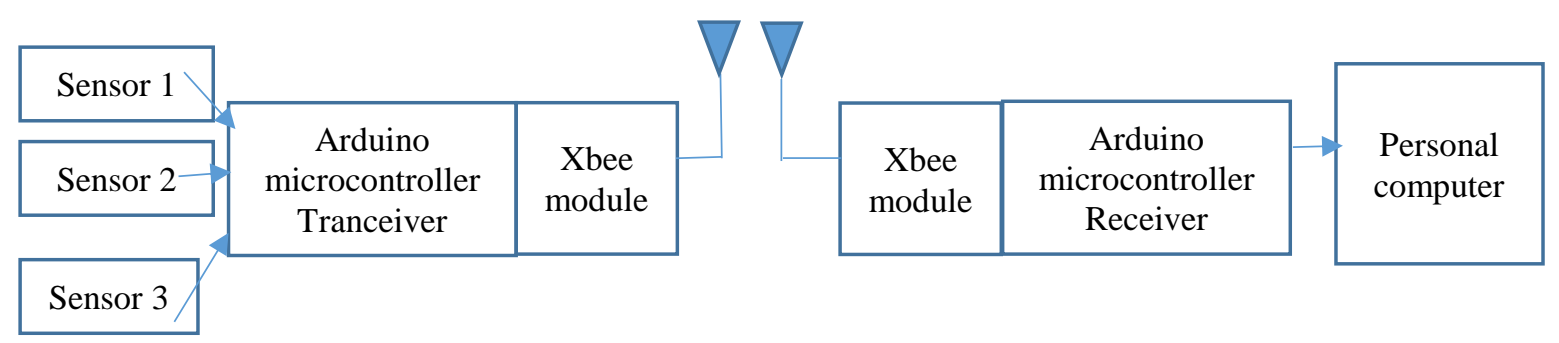

Fig. 1. Block diagram of the system.

The sensors for main soil parameters - $\mathrm{pH}$ (sensor 1). electrical conductivity (sensor 2) and moisture (sensor 3 ) are connected to the xbee wireless module and ATmega328P microcontroller that is the sensor node. The xbee wireless module provides very reliable communication between the microcontroller and the computer to visualize the information. The maximum data transmission rate is $250 \mathrm{kbps}$ and the maximum bandwidth is $1500 \mathrm{~m}$. The sensor node transmits the data to the receiver node. The receiver node with the microcontroller is connected to the personal computer station. The transmitted data are collected and saved in database that allow following data analysis.

\subsection{Hardware design of wireless system for measuring main soil indicators}


Design of system for monitoring of main soil quality parameters. require using the following sensors - for electrical conductivity, for moisture and $\mathrm{pH}$.

\section{A. Main parts of the system - microcontroller and xbee module}

Main microcontroller [7] (Figure 2a) is widely used open-source microcontroller board based on the ATmega328P microcontroller and developed by Arduino.cc. The board is equipped with sets of digital and analog input/output (I/O) pins that may be interfaced to various expansion boards (shields) and other circuits. The board features 14 digital pins and 6 analog pins. It is programmable with the Arduino IDE (Integrated Development Environment) via a type B USB cable. It can be powered by a USB cable or by an external 9 volt battery. though it accepts voltages between 7 and 20 volts. The Xbee [8] shield allows an Arduino board to communicate wirelessly using Zigbee. It is based on the Xbee module from Max Stream. The module can communicate up to 100 feet indoors or 300 feet outdoors (with line-of-sight). It can be used as a serial/usb replacement or you can put it into a command mode and configure it for a variety of broadcast and mesh networking options.

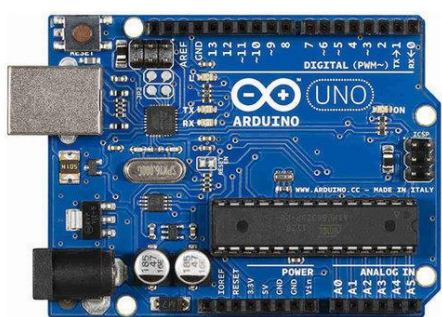

a)

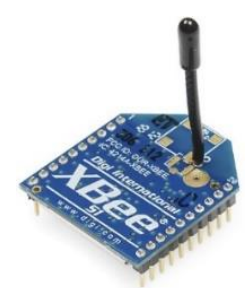

b)

Fig. 2. Arduino microcontroller and Xbee wireless module.

\section{B. Sensor for soil indicators measurement}

The sensors for measuring the main parameters of the soil ( $\mathrm{pH}$. electrical conductivity and humidity) are mainly used in the field of precision farming. Suitable similar sensors are shown on Figure 3. Their output signals are compatible with the analogue/digital inputs of the transmitter module. The sensors are pre-calibrated with calibration solutions for $\mathrm{pH}$ and electrical conductivity with accurate values.

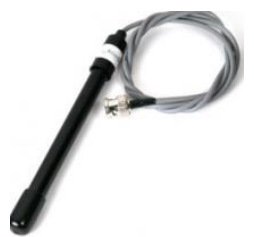

a)

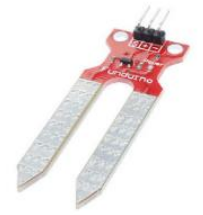

b)

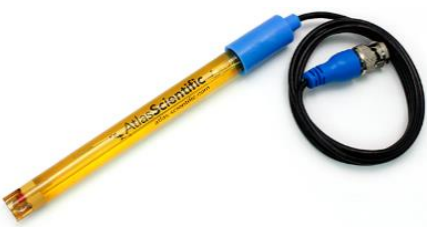

c)

Fig. 3. Sensors for measuring basic soil parameters: a) electrical conductivity; b) humidity; c) acidity.

Developed wireless system for soil indicators measurement is shown on Figure 4. For real measurement is need to know the measurement error of the system [9].

\subsection{Reference electronic device for soil indicators measurement}

Reference measurement are provide with device WTW-720 which is electronic device for laboratory measurement shown on Figure 5. WTW-720 is standard device for $\mathrm{pH}$. conductivity and temperature measurement in a laboratory conditions with a large multifunction display. This device has a high degree of accuracy and a large measuring range. It has a built-in temperature sensor. Measurement errors due to contact with the side walls or the base of the measuring vessels are not measured. there are no measurement errors due to the influence of the cable $[3,6]$. The WTW-720 has a $\mathrm{pH}$ range of -2.00 to 19.99 and an accuracy of $\pm 0.005 \%$ for measuring $\mathrm{pH}$ values. With a temperature range of -5 to $105{ }^{\circ} \mathrm{C}\left(23\right.$ to $\left.221{ }^{\circ} \mathrm{F}\right)$ and a temperature measurement accuracy of $\pm 0.1{ }^{\circ} \mathrm{C}$. When measuring electrical conductivity in aqueous solution. the measurement accuracy is \pm 0.005 . 


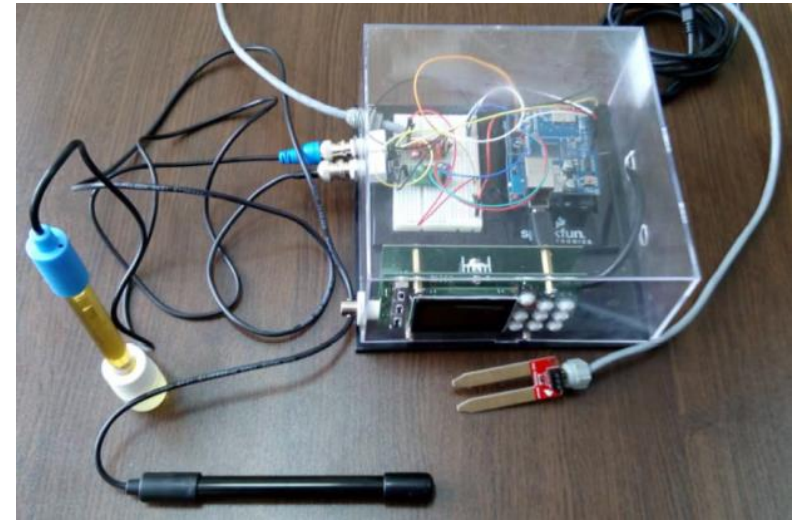

Fig. 4. Wireless system for soil indicators measurement.

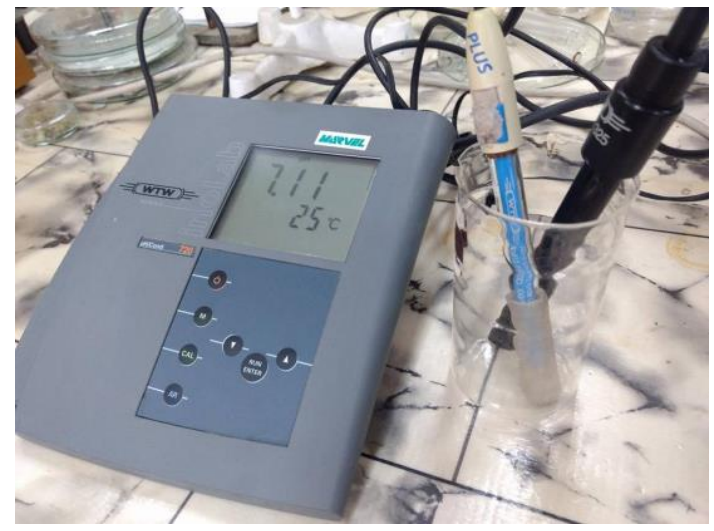

Fig. 5. WTW-720 standard meter for measuring electrical conductivity and $\mathrm{Ph}$.

\subsection{Experiment description}

The $\mathrm{pH}$ indicator determines the concentration and activity of the hydrogen cations in an aqueous suspension or aqueous extraction from the soil at a soil to water ratio of $1: 2.5$. The active acidity is determined by extraction from the soil in water or potassium chloride solution. The amount of free hydrogen ions in the soil solution is determined in the water extract and in the $\mathrm{KCl}$ extraction. the amount of hydrogen ions transferred to the soil solution is determined by the exchange processes between the KCI solution and the soil. A soil substrate by drawing $10 \mathrm{~g}$. air dry soil is prepared. sifted through $2 \mathrm{~mm}$ sieves and is placed in laboratory flasks. Next step is adding a $50 \mathrm{~mL}$ of deionized or distilled water and is placed on a shuffler for 1 hour. Conductometer is preliminary calibrated with $\mathrm{KCl}$ solution. The soil sample preliminary prepared are measured with developed and standard systems and the results for soil indicators are saved in database for calculation the error between obtained data.

\section{RESULTS AND DISCUSSION}

For the purpose of measurement. nine types of soils taken from different locations are used. The depth of the soil sample is $0-30 \mathrm{~cm}$ deep. Table 3 presents the measured $\mathrm{pH}$. conductivity and humidity values of the soil samples taken. For the purpose of the measurement. nine solutions were made in a ratio of the amount of soil and distilled water to 1: 2.5. The samples were first measured with standard system WTW-720 for measuring electrical conductivity and $\mathrm{pH}$ and then with developed wireless system for measuring $\mathrm{pH}$ and electrical conductivity with Arduino sensors (Figure 6).
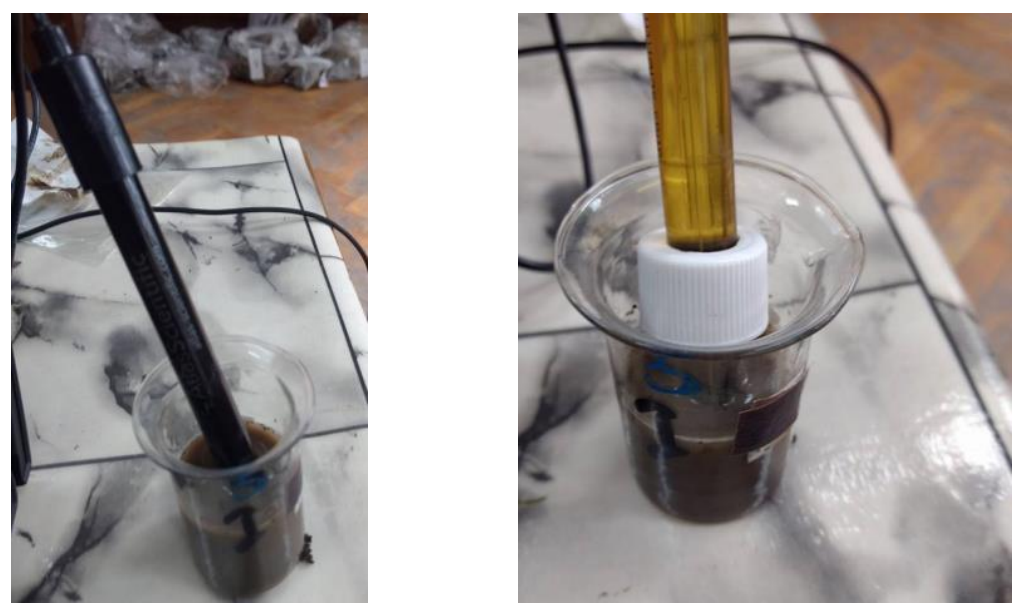

Fig. 6. Measurement of $\mathrm{pH}$ and electrical conductivity with Arduino sensors.

- Calculation of absolute error:

$$
\Delta(\mathrm{pH})=\left|\mathrm{pH}_{\text {sensor }}-\mathrm{pH}_{\mathrm{wtw}}\right|
$$




$$
\Delta(\mathrm{EC})=\left|\mathrm{EC}_{\text {sensor }}-\mathrm{EC}_{\mathrm{wtw}}\right|
$$

- Calculation of percentage relative error:

$$
\begin{aligned}
& \delta(\mathrm{pH})=\frac{\Delta(\mathrm{pH})}{\mathrm{pH}_{\mathrm{wtw}}} \cdot 100 . \% \\
& \delta(\mathrm{EC})=\frac{\Delta(\mathrm{EC})}{\mathrm{EC}_{\mathrm{wtw}}} \cdot 100 . \%
\end{aligned}
$$

Table 3 Measurement Data with WTW-720 and Arduino Sensors for pH. Humidity and Electroconductivity.

\begin{tabular}{|l|c|c|c|c|c|c|c|c|}
\hline \multirow{2}{*}{ Soil } & \multicolumn{2}{|c|}{ Arduino sensors } & \multicolumn{2}{|c|}{ WTW -720} & $\Delta(\mathrm{pH})$ & $\delta(\mathrm{pH})$ & $\Delta(\mathrm{EC})$ & $\delta(\mathrm{EC})$ \\
\cline { 2 - 10 } & $\mathrm{pH}$ & $\begin{array}{c}\mathrm{EC} . \\
\mathrm{mS} / \mathrm{m}\end{array}$ & $\mathrm{pH}$ & $\begin{array}{c}\mathrm{EC} \\
\mathrm{mS} / \mathrm{m}\end{array}$ & $\begin{array}{c}\text { Absolu } \\
\text { te } \\
\text { Error. } \\
\%\end{array}$ & $\begin{array}{c}\text { Relative } \\
\text { Error.\% }\end{array}$ & $\begin{array}{c}\text { Absolute } \\
\text { Error.\% }\end{array}$ & $\begin{array}{c}\text { Relative } \\
\text { Error.\% }\end{array}$ \\
\hline sandy soil - Varna & 7.85 & 104.07 & 7.93 & 100.60 & 0.08 & 1.01 & 3.47 & 3.45 \\
\hline soil from G. Ablanovo & 7.52 & 187.50 & 7.51 & 189.20 & 0.01 & 0.13 & 1.70 & 0.90 \\
\hline biohumus California worm & 7.83 & 845.30 & 7.96 & 842.00 & 0.13 & 1.63 & 3.30 & 0.39 \\
\hline fertilizer & 7.74 & 1147.00 & 7.92 & 1143.00 & 0.18 & 2.27 & 4.00 & 0.35 \\
\hline soil from Getsovo - 1 & 8.00 & 188.90 & 8.20 & 190.70 & 0.20 & 2.44 & 1.80 & 0.94 \\
\hline soil from Trastenik & 8.10 & 168.00 & 8.13 & 164.00 & 0.03 & 0.37 & 4.00 & 2.44 \\
\hline soil from Getsov - 2 & 8.14 & 156.40 & 8.20 & 157.70 & 0.06 & 0.73 & 1.30 & 0.82 \\
\hline
\end{tabular}

\section{CONCLUSIONS}

A wireless microprocessor system based on ATmega328P microcontroller and Arduino sensors for measurement of soil properties is developed. Main quality indicators of soil $\mathrm{pH}$ and conductivity of eight types of soils taken from different places in Bulgaria are measured. The developed wireless system is compared with standard reference device and percentage relative errors are calculated. The measurement error for electrical conductivity is in range from $0.35 \%$ to $3.45 \%$. and for $\mathrm{pH}$ - from $0.13 \%$ to $2.44 \%$. The relative errors for the variation of $\mathrm{pH}$ and conductivity obtained for all soil samples are lower than the maximum allowable. This is an indicator for the effectiveness of the developed wireless system for measurement of quality soil indicators. The electrical conductivity sensor depend on the calibration and the temperature. Using more frequent calibration and temperature compensation will improve measurement and decrease the errors. Although the variation in the relative error values. the system applies an adequate measurement of soil $\mathrm{pH}$ and conductivity for precise agriculture.

\section{ACKNOWLEDGEMENT}

The present paper has been produced with the financial support of the project No 2018 - FEEA-03 „Research and modeling of growing. processing and qualifying of food products". financed by "Scientific Research Fund" at University of Ruse.

\section{REFERENCES}

[1] Raiesi, F., Kabir, V., Identification of soil quality indicators for assessing the effect of different tillage practices through a soil quality index in a semi-arid environment, Ecological Indicators, vol. 71. 2016, p. 198-207.

[2] Evstatiev, D., Evlogiev, Y., Landslides along the northern Black sea coast between Varna city and Kavarna town, Geo-Eco-Marina, vol. 19., 2013, p. 39-57.

[3] Mohd - Aizat, A., Mohamad - Roslan, M.K., Sulaiman, W.N.A., Karam, D.S., The relationship between soil $\mathrm{pH}$ and selected soil properties in 48 years logged - over forest, International journal of environmental sciences,. vol. 4, no. 6, 2014, p. $1129-1140$.

[4] Grisso, R., Alley, M., Holshouser, D., Tomason, W., Precision farming tools: Soil electrical conductivity. VirginiaTech, 2009. 
[5] Balakrishna, K., Nethravathi, S.N., Harshitha, K., Real - Time soil monitoring system for the application of agriculture, International Journal of Engineering Science and Computing, vol. 6, no. 5, p. 2016. 5326 - 5331.

[6] Todorova, M., Atanasova, S., Near infrared spectra and soft independent modelling of class analogy for discrimination of Chernozems, Luvisols and Vertisols, Journal of Near Infrared Spectroscopy, vol. 24, no.3, 2016, p. 271-280.

[7] https://datasheet.octopart.com/A000066-Arduino-datasheet-38879526.pdf

[8] https://www.arduino.cc/en/Guide/ArduinoXbeeShield

[9] Kadirova, S. Y., Regulating the moisture of oilseed material in a toaster for vegetable oil extraction, INMATEH - Agricultural Engineering, no. 3, 2016, pp. 99-104. 